\title{
Effective Therapy Using Voglibose for Nonalcoholic Steatohepatitis in a Patient with Insufficient Dietary and Exercise Therapy: Exploring Other Treatment Possibilities
}

\author{
Kazuki Nagai ${ }^{\mathrm{a}}$ Katsuhiko Matsumaru ${ }^{\mathrm{a}}$ Yutaka Takahashi $^{\mathrm{b}}$ \\ Noriko Nakamurac \\ ${ }^{a}$ Nagai Clinic, bivision of Gastroenterology, Department of Internal Medicine, \\ and 'Department of Pathology, Saiseikai Yokohama-shi Nanbu Hospital, \\ Yokohama, Japan
}

\section{Key Words}

Voglibose - Nonalcoholic steatohepatitis - Insufficient dietary and exercise therapy

\begin{abstract}
A 56-year-old Japanese female with a 10-year history of thyroiditis presented to our institution. The laboratory data and clinical findings suggested that the patient had complicated nonalcoholic fatty liver disease or nonalcoholic steatohepatitis (NASH) with autoimmune hepatitis according to the criteria by the application of the International Autoimmune Hepatitis score. The patient could not manage by herself so dietary- and exercise-based treatment was difficult. Accordingly, ursodeoxycholic acid and ezetimibe therapy was started and continued until the performance of a liver needle biopsy to define the diagnosis. However, no improvement in liver function was observed. In addition, pathological findings indicated that the patient had NASH. The patient was finally diagnosed as having NASH. Therefore, voglibose was added to the ursodeoxycholic acid and ezetimibe therapy, and this addition of voglibose actually took effect. The patient's serum aspartate transaminase and alanine aminotransferase levels decreased dramatically. This report is the first to document other treatment possibilities of NASH in a case when dietary therapy is difficult.
\end{abstract}




\section{Introduction}

Nonalcoholic fatty liver disease (NAFLD) is one of the most common metabolic liver diseases in the world, encompassing simple steatosis to nonalcoholic steatohepatitis (NASH), advanced fibrosis, cirrhosis, and hepatocellular carcinoma. NAFLD affects a significant part of the general population worldwide [1]. The 'two hit' hypothesis is currently the prevailing theory for the development of NAFLD and NASH. The 'first hit' is purported to be the increase in free fatty acids in hepatocytes, which results in a decrease of beta oxidation. The second step includes various mechanisms contributing to the development of necroinflammation and fibrosis [1-6].

Ezetimibe is a novel and selective cholesterol absorption inhibitor that reduces plasma low-density lipoprotein cholesterol by selectively binding to the intestinal cholesterol transporter Niemann-Pick C1-Like 1 (NPC1L1). Chronic ezetimibe treatment significantly decreases plasma alanine aminotransferase activity, tumor necrosis factor (TNF- $\alpha$ ), and insulin resistance $[7,8]$. Nonetheless, no treatment for NASH has yet been established, except for dietary- and exercise-based treatment. The recommended treatment for NASH involves weight reduction through dietary and exercise therapy; however, this often proves to be difficult for outpatients. The patient in our case underwent insufficient dietary and exercise therapy.

We herein report our experience with a clinically suspected autoimmune hepatitis (AIH) case which turned out to be NASH according to the result of needle biopsy. This report also presents the improvements observed on liver function when voglibose was added to ursodeoxycholic acid (UDCA) and ezetimibe therapy. So far, this is the only such case that has been reported, but more cases should be investigated to determine whether this combination represents a suitable treatment for NASH. Our findings may be helpful for the future treatment of NASH.

\section{Case Report}

A 56-year-old Japanese female with a 10-year history of chronic thyroiditis visited our clinic, where she had been previously treated for a liver injury. She had experienced chronically elevated alanine aminotransferase (ALT) since April 2004. She had visited another hospital for recovery, however, she had not received any treatment at that time, and her liver injury had remained untreated. The patient visited our clinic on August 7, 2009. She had no habitual drinking habit, and she had never received a blood transfusion. Her family history was unremarkable. A physical examination at the time of onset showed the patient to be well nourished; her height was $156 \mathrm{~cm}$, her weight was $86 \mathrm{~kg}$, her waist circumference was $92 \mathrm{~cm}$, and her body mass index (BMI) was $35.4 \mathrm{~kg} / \mathrm{m}^{2}$. There was slight exophthalmos in her left eye. Her thyroid gland was slightly enlarged. Her chest and heart were normal, and no abdominal tumor or hepatosplenomegaly were observed. There was no remarkable swelling in her lymph nodes or peripheral edema in her extremities. Her neurologic function was normal.

The laboratory data recorded during the visit to our clinic were as follows: Hematologic tests were within the normal limits. Serological data included immunoglobulin G (IgG) was 2,172 mg/dl (normal 870-1,700 mg/dl), IgA was $584 \mathrm{mg} / \mathrm{dl}$ (normal 90-440 mg/dl), IgM was $134 \mathrm{mg} / \mathrm{dl}$ (normal $50-350 \mathrm{mg} / \mathrm{dl}$ ), the zinc sulfate turbidity test showed 10.6 KU (normal 4.2-12.2 KU), aspartate transaminase (AST) was 93 IU/l (normal 10-40 IU/l), ALT was $105 \mathrm{IU} / 1$ (normal 5-45 IU/l), lactic dehydrogenase was $263 \mathrm{IU} / \mathrm{l}$ (normal 120-245 IU/l), alkaline phosphatase (ALP) was $310 \mathrm{IU} / \mathrm{l}$ (normal 93-271 IU/l), $\gamma$-GTP was 263 IU/l (normal 8-60 IU/l), high-density lipoprotein cholesterol was $49 \mathrm{mg} / \mathrm{dl}$ (normal 40-77 mg/dl), triglycerides were $242 \mathrm{mg} / \mathrm{dl}$ (normal 40-149 mg/dl), low-density lipoprotein cholesterol was $119 \mathrm{mg} / \mathrm{dl}$ (normal 70-139 mg/dl), fasting blood sugar was $93 \mathrm{mg} / \mathrm{dl}$ 
(normal 78-108 mg/dl), hemoglobin A1c was 5.1\% (normal 4.5-5.8\%), and insulin was $17.7 \mu \mathrm{U} / \mathrm{ml}$ (normal 5-10 $\mu \mathrm{U} / \mathrm{ml}$ ). Homeostasis model assessment insulin resistance (HOMA-R) was 4.06.

Her thyroid function tests showed her free thyroxine level to be $1.03 \mathrm{ng} / \mathrm{dl}$ (normal $0.8-1.7 \mathrm{ng} / \mathrm{dl}$ ), and her thyroid-stimulating hormone level was $3.30 \mu \mathrm{IU} / \mathrm{ml}$ (normal $0.35-3.73 \mu \mathrm{IU} / \mathrm{ml}$ ). Autoantibody tests were positive for anti-nuclear antibody. However, autoantibody tests were negative for the rheumatoid arthritis test, lupus erythematosus test, anti-DNA antibody, anti-mitochondrial antibody, and anti-LKM-1 antibody. The results were negative for anti-hepatitis B surface Ag, hepatitis C antibody, and cytomegalovirus. Serum HCV-RNA and HBV-DNA were also negative. Abdominal ultrasonographic examinations, performed soon after the visit to our clinic, revealed severe fatty liver.

The clinical features and abdominal ultrasonography findings suggested NAFLD or NASH complicated with AIH. AIH could be assumed by the application of the International Autoimmune Hepatitis (IAH) score. Her IAH score was 13. Her IAH score suggested probable AIH (for scores 10-15) before treatment [2]. The diagnosis at that time was NAFLD complicated with probable AIH.

On August 7, 2009, UDCA and ezetimibe, which have a suppressive effect on fatty liver, were started at an initial dose of 600 and $10 \mathrm{mg}$, respectively. This treatment continued until the performance of a liver needle biopsy to define the diagnosis. Nevertheless, no recovery of liver function was observed during this period (fig. 1). On December 11, after 12 weeks of UDCA and ezetimibe therapy, her serum levels of AST, ALT, ALP, and $\gamma$-GTP had not decreased.

To rule out the possibility of AIH, a liver needle biopsy was performed on December 21, 2009. The sample showed extensive periportal fibrosis (fig. 2). The fatty infiltration was predominantly macrovesicular; however, some microvesicular steatosis could also be seen. There were few balloon cells with intracytoplasmic hepatocytes, but no Mallory bodies or granulomas were seen. Although the infiltration of neutrophils was observed in the intralobular space, the infiltration of plasma cells could not be seen in the sinusoidal space (fig. 3 ). A few glycogenated nuclei were observed. Collections of inflammatory cells were also observed in addition to the macro- and microvesicular steatosis (fig. 4 ). The NASH score was grade 2, stage 2 according to the criteria proposed by Brunt et al. [3].

The patient was finally diagnosed as having NASH complicated with AIH. According to the results of the liver needle biopsy, the main cause of the liver injury was NASH and not AIH. Therefore, voglibose was added to the UDCA and ezetimibe therapy on January 7, 2010, and this addition of voglibose actually took effect. The serum hepatobiliary enzyme levels, including AST, ALT, ALP and $\gamma$-GTP, decreased dramatically following this treatment. Laboratory tests on June 4, 2010 were as follows: AST 40 IU/l, ALT 30 IU/l, ALP 276 IU/l, and $\gamma$-GTP 74 IU/l. Her fasting blood sugar was $93 \mathrm{mg} / \mathrm{dl}$, hemoglobin A1c was 4.7\%, insulin was $11.8 \mu \mathrm{U} / \mathrm{ml}$, and HOMA-R was 2.71. Follow-up ultrasounds were performed, but the fat in the liver remained unchanged. There was no remarkable change in her BMI $\left(35.4 \mathrm{~kg} / \mathrm{m}^{2}\right)$ during this clinical course.

This case is thought to be a variation of clinically diagnosed AIH which was later found pathologically to demonstrate NASH. In addition, it is also important to note that this report demonstrates the markedly effective combination therapy of UDCA, ezetimibe, and voglibose for the treatment of this patient with NASH.

\section{Discussion}

The recommended treatment for NASH involves weight reduction through dietary and exercise therapy; however, this often proves to be difficult for outpatients. Our patient underwent insufficient dietary and exercise therapy. Furthermore, hospitalization for educational purposes, including dietary and exercise therapy, is nearly impossible because of the economic burden it presents to most patients. Therefore, various treatments, such as vitamin C, vitamin E, rosuvastatin, and UDCA [4-7] have been reported; however, the effects of these treatments have not yet been established. The NPC1L1 inhibitor ezetimibe has a suppressive effect on fatty liver [8-12], but there is insufficient evidence to 
determine whether ezetimibe suppresses the 'second hit'. The mechanism of its suppressive effect on fatty liver still remains to be elucidated.

In our case, combination therapy with UDCA and ezetimibe did not improve the patient's hepatitis. After performance of a needle biopsy, when the patient was identified as having NASH, we added voglibose to the UDCA and ezetimibe therapy. Voglibose was added for the treatment of this case because there was a decrease in the patient's insulin sensitivity, and glucagon-like peptide 1 (GLP-1) is reported to be related to NASH. In addition, insulin resistance is nearly universal in NASH patients. Given that insulin resistance plays a dominant role in the pathogenesis of the condition, many studies have examined the use of insulin sensitizers in NASH $[13,14]$. Voglibose effectively activates GLP-1 [15-17], but it should be noted that the long-term treatment with voglibose can cause bile cholestasis [18]. Voglibose was added in this case because HOMA-R, the index of insulin resistance, showed a high level of 4.06. After voglibose treatment, the patient's HOMA-R decreased to 2.71. The cause of the improvement of the patient's NASH may be due to improvements in insulin sensitivity and postprandial hyperglycemia.

It is unclear how voglibose improved the patient's hepatitis, but it may have decreased the production of free radicals, thereby causing a reduction in the mRNA and protein expression of the hepatic inflammatory cytokine, TNF- $\alpha$. In our case, voglibose may have lessened insulin resistance too, and its addition dramatically improved the patient's liver function. However, in order to use voglibose in other patients, a full understanding of its ability to worsen liver function is needed. No paired biopsy was performed in our case, but we observed a decrease in the level of both ALT and AST, meaning that the inflammation of the liver could be controlled.

This report is about other treatment possibilities to manage NASH, using a markedly effective combination therapy with UDCA, ezetimibe, and voglibose. So far, this is the only such case that has been reported, but more cases should be investigated to determine whether this combination represents a suitable treatment for NASH.

\section{Conclusions}

(1) We herein report our experience with a clinically suspected AIH case which turned out to be NASH according the result of needle biopsy. (2) Controlling hepatitis with drug intervention should be done prudently. (3) Only one case of combination treatment of NASH with UDCA, ezetimibe, and voglibose has been reported so far, thus more cases should be investigated to determine whether this may represent an effective treatment for NASH. A strict follow-up is recommended in such cases. 
Serum hepatobiliary enzyme and BMI changes during clinical course

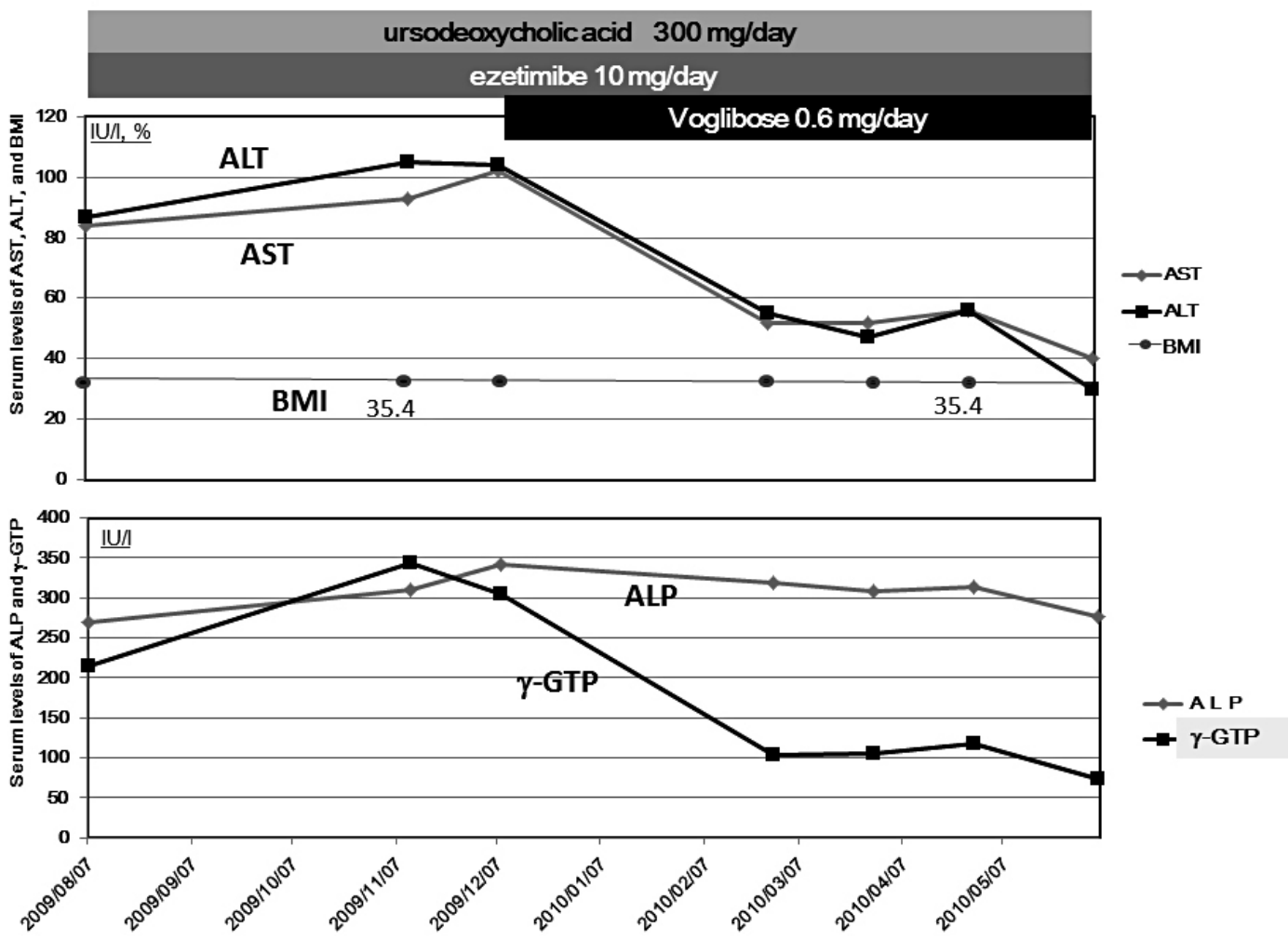

Fig. 1. Changes in serum hepatobiliary enzyme levels and BMI during the clinical course. In this case, UDCA and ezetimibe therapy was started at an initial dose of 600 and $10 \mathrm{mg}$, respectively, on August 7, 2009. No recovery of the liver was observed. According to the results of liver needle biopsy, combination therapy with UDCA, ezetimibe, and voglibose was started on January 7,2010. The serum hepatobiliary enzyme levels, including AST, ALT, ALP, and $\gamma$-GTP, decreased dramatically following treatment. Laboratory data obtained on June 4, 2010 were as follows: AST 40 IU/l, ALT 30 IU/l, ALP 276 IU/l, and $\gamma$-GTP 74 IU/l. There was no remarkable changed in BMI during the clinical course. 


\begin{tabular}{r|l|l|l} 
Case Reports in & Case Rep Gastroenterol 2011;5:336-343 \\
GOl: 10.1159/000329346 & $\begin{array}{l}\text { Published online: } \\
\text { June 10, 2011 }\end{array}$ & $\begin{array}{l}\text { O 2011 S. Karger AG, Basel } \\
\text { ISSN 162-20631 } \\
\text { www.karger.com/crg }\end{array}$ \\
\hline
\end{tabular}

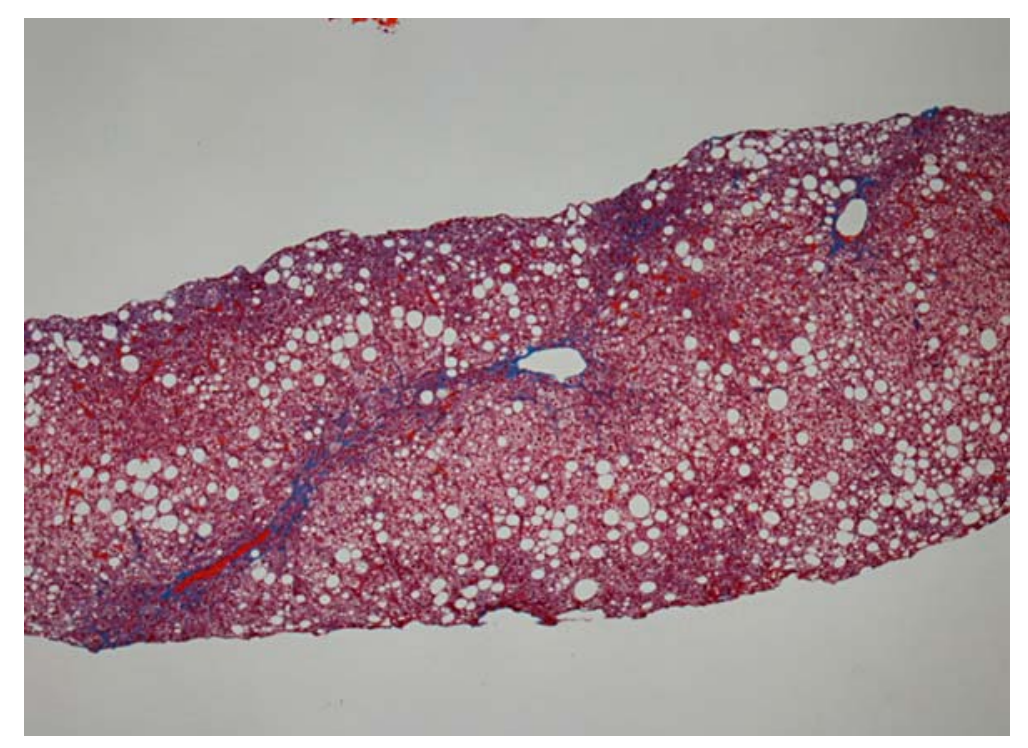

Fig. 2. A liver needle biopsy sample. Extensive periportal fibrosis was seen (Masson trichrome stain). The fatty infiltration was predominantly macrovesicular; however, some microvesicular steatosis could also be seen. There were few balloon cells with intracytoplasmic hepatocytes. No Mallory bodies or granulomas were seen.

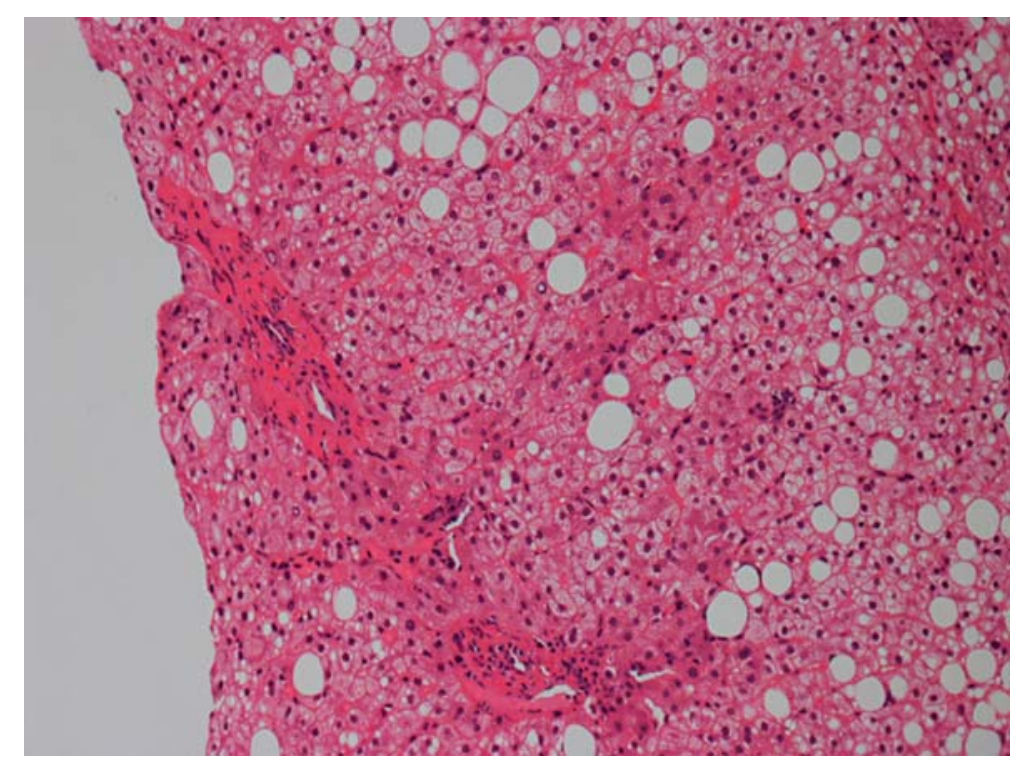

Fig. 3. A liver needle biopsy sample. The infiltration of neutrophils was observed in the intralobular space, however, the infiltration of plasma cells in the sinusoidal space was not observed (hematoxylin and eosin stain). 


\begin{tabular}{r|l|l|l}
$\begin{array}{r}\text { Case Reports in } \\
\text { Gastroenterology }\end{array}$ & $\begin{array}{l}\text { Case Rep Gastroenterol 2011;5:336-343 } \\
\text { Dol: 10.1159/000329346 }\end{array}$ & $\begin{array}{l}\text { Published online: } \\
\text { June 10, 2011 }\end{array}$ & $\begin{array}{l}\text { O 2011 S. Karger AG, Basel } \\
\text { ISSN 1662-0631 } \\
\text { www.karger.com/crg }\end{array}$ \\
\hline
\end{tabular}

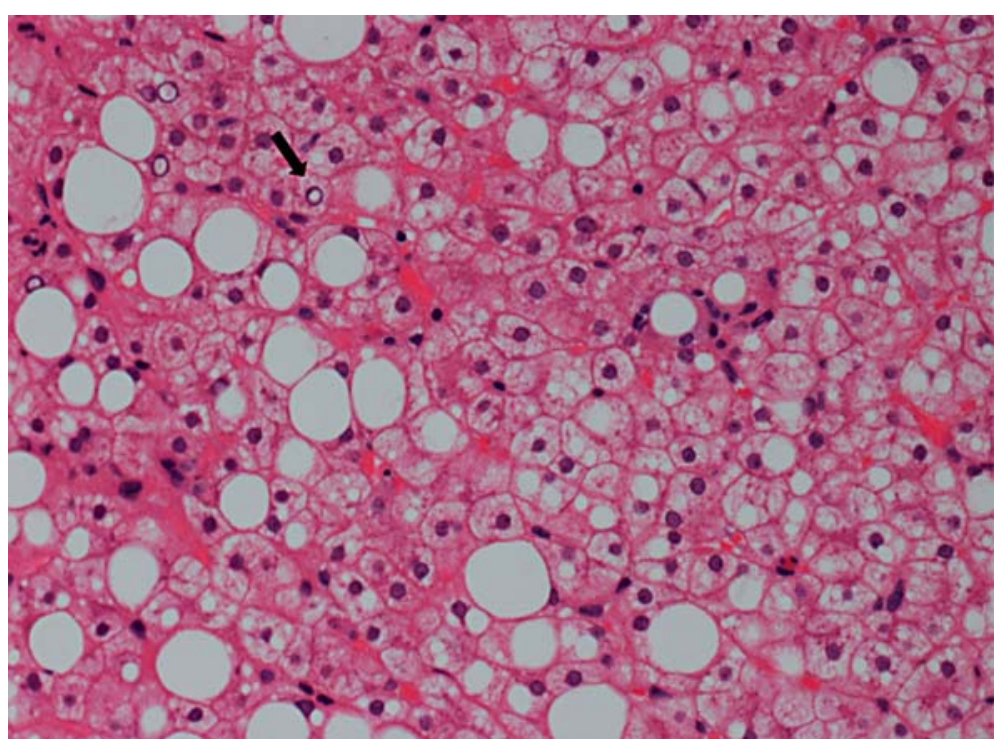

Fig. 4. A liver needle biopsy sample. A few glycogenated nuclei were observed (arrow). Collections of inflammatory cells were also observed in addition to the macro- and microvesicular steatosis (hematoxylin and eosin stain). The NASH score was grade 2, stage 2 according to the criteria proposed by Brunt et al. [3].

\section{References}

1 Sevastianos VA, Hadziyannis SJ: Nonalcoholic fatty liver disease: from clinical recognition to treatment. Expert Rev Gastroenterol Hepatol 2008;2:59-79.

2 Johnson PJ, McFarlane IG: Meeting report: International Autoimmune Hepatitis Group. Hepatology 1993; 18:998-1005.

-3 Brunt EM, Janney CG, Di Bisceglie AM, Neuschwander-Tetri BA, Bacon BR: Nonalcoholic steatohepatitis: a proposal for grading and staging the histological lesions. Am J Gastroenterol 1999;94:2467-2474.

$\checkmark 4$ Bernal-Reyes R, Escudero RB: Treatment of non-alcoholic steatohepatitis (NASH). A comparative study of ursodeoxycholic acid and alpha-tocopherol. A preliminary report. Rev Gastroenterol Mex 2002;67:70-75.

-5 Sorrell MF, Mukherjee S: Non-alcoholic steatohepatitis (NASH). Curr Treat Options Gastroenterol 1999;2:447-450.

6 Harrison SA, Ward JA, Schenker S: The role of vitamin E and C therapy in NASH. Am J Gastroenterol 2004;99:1862.

7 Yoneda M, Hasegawa T, Nakamura K, Tamano M, Kono T, Terano A: Vitamin E therapy in patients with NASH. Hepatology 2004;39:568; author reply 569-570.

8 Nomura M, Ishii H, Kawakami A, Yoshida M: Inhibition of hepatic Niemann-Pick C1-Like 1 improves hepatic insulin resistance. Am J Physiol Endocrinol Metab, Epub ahead of print.

9 Nozaki Y, Fujita K, Yoneda M, et al: Long-term combination therapy of ezetimibe and acarbose for non-alcoholic fatty liver disease. J Hepatol 2009;51:548-556.

10 Abel T, Feher J, Dinya E, Gamal Eldin M, Kovacs A: Efficacy and safety of ezetimibe/simvastatin combination therapy in patients with type 2 diabetes and nonalcoholic fatty liver disease. Orv Hetil 2009;150:989-993.

11 Zheng S, Hoos L, Cook J, et al: Ezetimibe improves high fat and cholesterol diet-induced non-alcoholic fatty liver disease in mice. Eur J Pharmacol 2008;584:118-124.

12 Deushi M, Nomura M, Kawakami A, et al: Ezetimibe improves liver steatosis and insulin resistance in obese rat model of metabolic syndrome. FEBS Lett 2007;581:5664-5670.

-13 Stein LL, Dong MH, Loomba R: Insulin sensitizers in nonalcoholic fatty liver disease and steatohepatitis: current status. Adv Ther 2009;26:893-907. 
14 Kashi MR, Torres DM, Harrison SA: Current and emerging therapies in nonalcoholic fatty liver disease. Semin Liver Dis 2008;28:396-406.

-15 Moritoh Y, Takeuchi K, Hazama M: Combination treatment with alogliptin and voglibose increases active GLP-1 circulation, prevents the development of diabetes and preserves pancreatic beta-cells in prediabetic $\mathrm{db} / \mathrm{db}$ mice. Diabetes Obes Metab 2010;12:224-233.

-16 Moritoh Y, Takeuchi K, Hazama M: Chronic administration of voglibose, an alpha-glucosidase inhibitor, increases active glucagon-like peptide- 1 levels by increasing its secretion and decreasing dipeptidyl peptidase- 4 activity in ob/ob mice. J Pharmacol Exp Ther 2009;329:669-676.

17 Göke B, Fuder H, Wieckhorst G, Theiss U, Stridde E, Littke T, Kleist P, Arnold R, Lücker PW: Voglibose (AO-128) is an efficient alpha-glucosidase inhibitor and mobilizes the endogenous GLP-1 reserve. Digestion 1995;56:493-501.

18 Kawakami S, Arima T, Harada K, et al: Hepatic necrosis with cholestasis induced by long-term voglibose administration. Intern Med 2001;40:484-488. 